\title{
Effects of Different Concentrations of Selenium on Antioxidant Enzyme Activity of Perilla frutescens
}

\author{
Huan Yao ${ }^{1, a}$, Liying Ouyang, ${ }^{2, b}$, Ming'an Liao ${ }^{1, c}$ and Lijin Lin ${ }^{3, d *}$ \\ ${ }^{1}$ College of Horticulture, Sichuan Agricultural University, Chengdu, Sichuan, China \\ 2Department of Modern Agriculture, Chendu Agricultural College, Chengdu, Sichuan, China \\ 3Institute of Pomology and Olericulture, Sichuan Agricultural University, Chengdu, Sichuan, China \\ a272365026@qq.com, b24983471@qq.com, Iman@sicau.edu.cn, dllj800924@qq.com \\ ${ }^{*}$ Corresponding author.
}

Keywords: Selenium; Perilla frutescens; Antioxidant enzyme activity

\begin{abstract}
A pot experiment was conducted to study the effects of different concentrations of selenium (Se) on the antioxidant enzyme activity of Perilla frutescens. The results showed that Se treatment had significant effect on activities of SOD, POD, CAT and soluble protein content. With Se concentrations increased, activities of SOD, POD and CAT showed different trends, but when Se concentration was $100 \mathrm{mg} / \mathrm{kg}$, activities of SOD, POD, CAT reached the peak, which increased by $92.80 \%, 2260.97 \%$ and $45.56 \%$ compared with control respectively. However, soluble protein content reached the peak when Se concentration was $75 \mathrm{mg} / \mathrm{kg}$, which was increased by $80.28 \%$. Therefore, Se can improve antioxidant enzyme activity and soluble protein content of $P$. frutescens. In terms of antioxidant enzyme activity, Se concentration of $100 \mathrm{mg} / \mathrm{kg}$ was the best. However, in terms of soluble protein content, Se concentration of $75 \mathrm{mg} / \mathrm{kg}$ was the best.
\end{abstract}

\section{Introduction}

Perilla frutescens is an annual plant that is widely distributed throughout Korea, China, and Japan. Its leaves are used as a garnish and colorant for foods and as a traditional medicine for the treatment of asthma, cough, sore throat, dyspersia, insomnia, and diabetes [1]. Selenium (Se) is needed for plants as well as animals and humans [2]. Se is associated with the oxygen-sulfur-tellurium group and plants usually enable transfer from soil to the food chain [3]. So human can get from edible parts of plants. Se deficiency can result from poor dietary intake of Se and can be induced or aggravated by certain types of stresses - nutritional, chemical, and infectious. If people lack Se, they may suffer from Keshan disease, Kashin-Beck disease and cancer [4]. Most of the Se in plant foods is present in the organic, although inorganic forms are also bioavailable [5]. However, it is essential to know the form of Se ingested because inorganic Se causes toxic concentrations much lower than organic Se [6]. With the improvement of living standards, people are paying more and more attention to the nutrition of food, and the intake of Se is increasingly attracting people's attention. Vegetables are cheap and require daily intake. Therefore, it is very convenient for people to consume Se through vegetables. Research has shown that Se can play a protective role during high temperature stress by enhancing the antioxidant defense system [7]. Therefore, this experiment used different concentrations of Se to study the changes of antioxidant enzyme activities (SOD, POD and CAT) and soluble protein content of $P$. frutescens in Se-containing soil.

\section{Materials and Methods}

Materials. The experiments were conducted at Sichuan Agricultural University $\left(30^{\circ} 42^{\prime} \mathrm{N}, 103^{\circ} 51^{\prime}\right.$ E), Wenjiang, Chengdu, Sichuan, China. P. frutescens seeds are purchased from the market. Se is purchased from Chengdu Kelong chemical reagent factory. All chemicals used in experiments were of analytical grade.

Experimental Design. The soil samples were air-dried and passed through a 5-mm mesh in April 
2017 , and then $3.0 \mathrm{~kg}$ of soil was weighed into each polyethylene pot $18 \mathrm{~cm} \times 26 \mathrm{~cm}$ (height $\times$ diameter). $\mathrm{Na}_{2} \mathrm{O}_{3} \mathrm{Se} \cdot 5 \mathrm{H}_{2} \mathrm{O}$ solution was added to the soil to divide the Se content into 0 (control), 5, $10,25,50,75$ and $100 \mathrm{mg} / \mathrm{kg}$. The soils were mixed immediately and again after 4 weeks, during this period soil moisture was kept at $80 \%$. Seeds were sterilized in $10 \% \mathrm{Na}_{3} \mathrm{PO}_{4}$ solution for 5 min, rinsed in distilled water five times, and were placed on 9-cm-diameter Petri dishes with three layers of filter paper moistened with distilled water and germinated at $25^{\circ} \mathrm{C}$ in darkness. Seeds were considered germinated when the seed coat was broken and a radical was visible. After germination, seeds were planted in seedling tray filled with nursery substrate. When the third leaf expanded, uniform seedlings were transplanted into the previously prepared polyethylene pots, four plants seedlings per pot, each treatment repeated three times, randomly placed, and routinely administered. After one month of plants growing, the upper young shoots $(2 \mathrm{~cm}$ in length) were collected to determine the superoxide dismutase (SOD) activity, peroxidase (POD) activity, catalase (CAT) activity and soluble protein content [8].

Statistical Analyses. Statistical analysis was carried out by using SPSS 20.0 statistical software. The data were analyzed by one-way ANOVA, with the least significant difference at the 5\% confidence level.

\section{Results and Discussion}

SOD Activity of $\boldsymbol{P}$. frutescens. Se treatment had significant effect on SOD activity (Fig. 1). With Se concentrations increased, SOD activities increased firstly, and then decreased, increased lastly, and reached the peak when soil Se concentration was $100 \mathrm{mg} / \mathrm{kg}$. Compared with control, when Se concentrations were $5,75,100 \mathrm{mg} / \mathrm{kg}$, SOD activities were significantly increased, which increased by $30.31 \%, 36.90 \%$ and $92.80 \%$ respectively. However, when Se concentrations were 10, 25 and 50 $\mathrm{mg} / \mathrm{kg}$, there were no obvious differences.

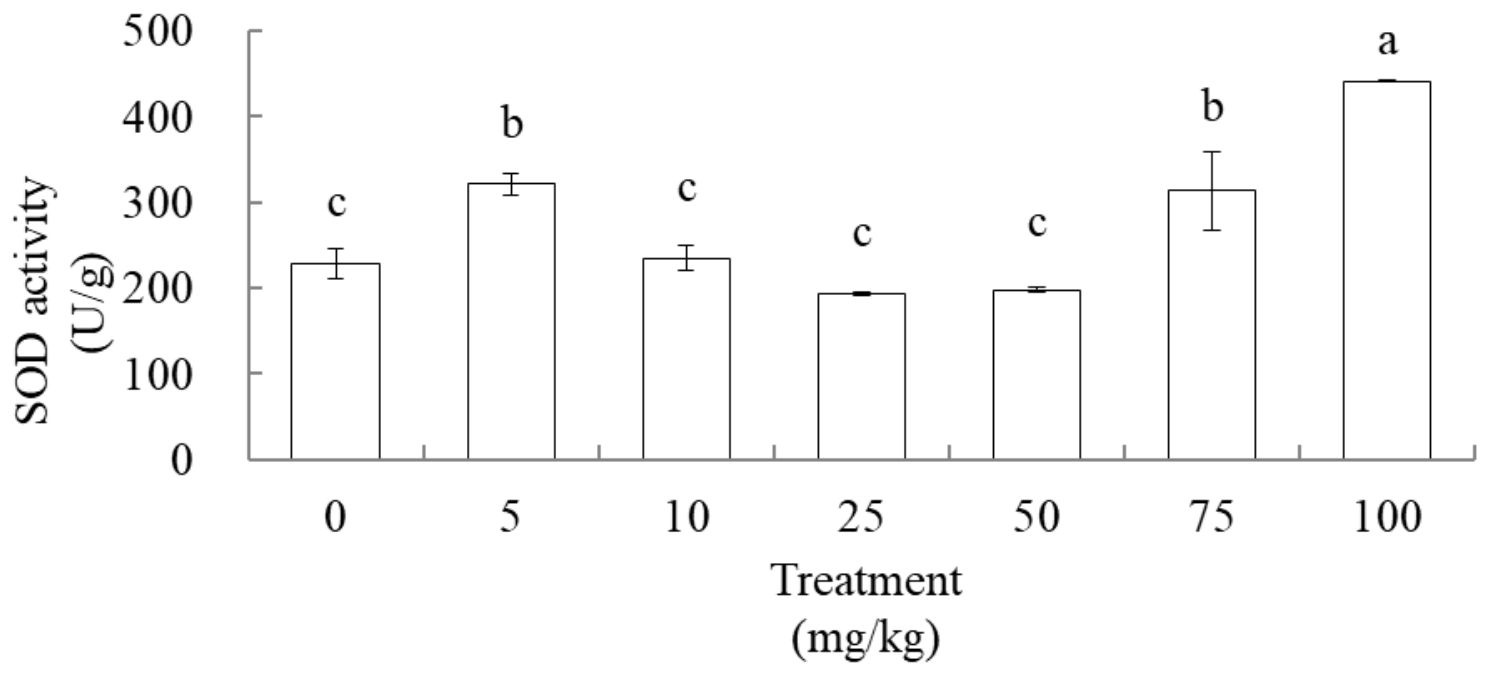

Fig. 1 SOD activity of $P$. frutescens

Note: there is a significant difference between 0.05 levels of different letters, the same as following tables.

POD Activity of $\boldsymbol{P}$. frutescens. Fig. 2 showed that POD activities increased firstly, decreased next, increased finally. And when Se concentration was $100 \mathrm{mg} / \mathrm{kg}$, POD activity reached the peak. Within the range of $0-10 \mathrm{mg} / \mathrm{kg}$, there were no significant differences in POD activities. However, within the range of $25-100 \mathrm{mg} / \mathrm{kg}$, POD activities were significantly increased by $283.25 \%$, $178.18 \%, 691.23 \%$ and $2260.97 \%$ respectively.

CAT Activity of $\boldsymbol{P}$. frutescens. As shown in Fig. 3, there were no significant differences within the range of $0-75 \mathrm{mg} / \mathrm{kg}$. Only when Se concentration was $100 \mathrm{mg} / \mathrm{kg}$, CAT activity increased by 
$45.56 \%$ compared with control.

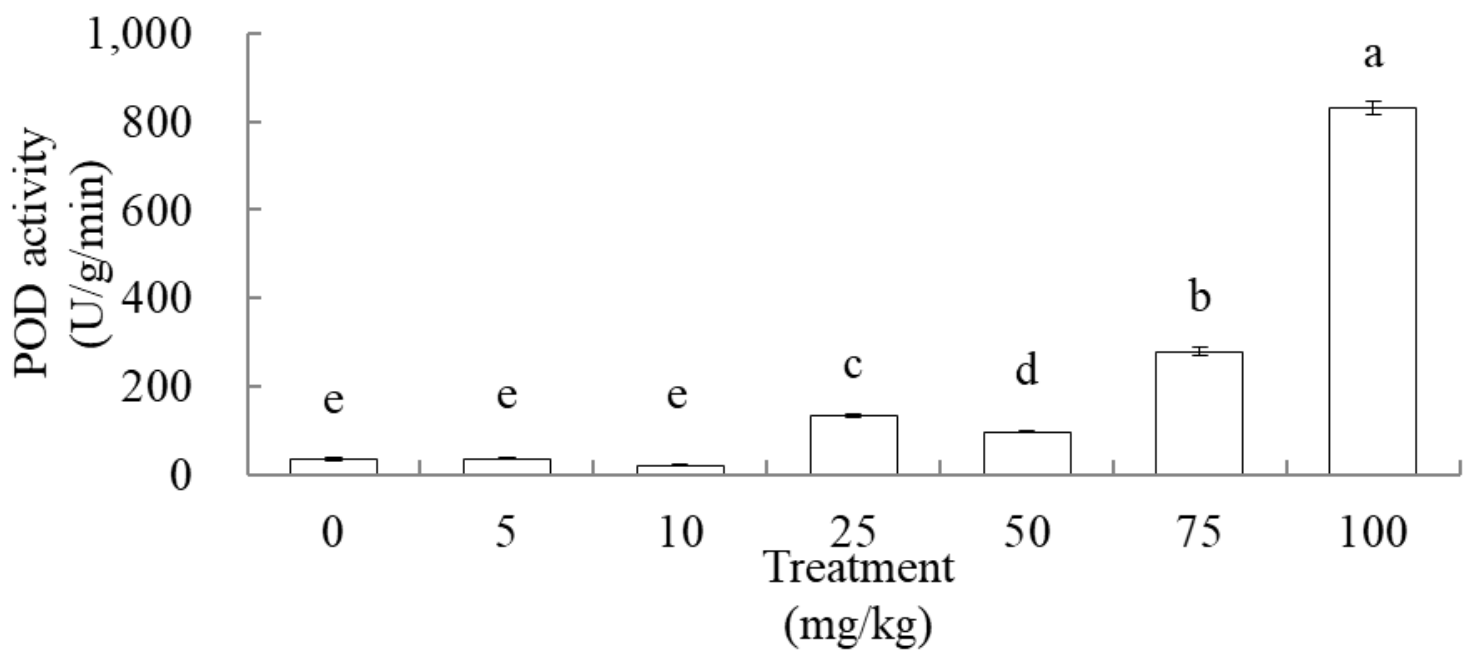

Fig. 2 SOD activity of $P$. frutescens

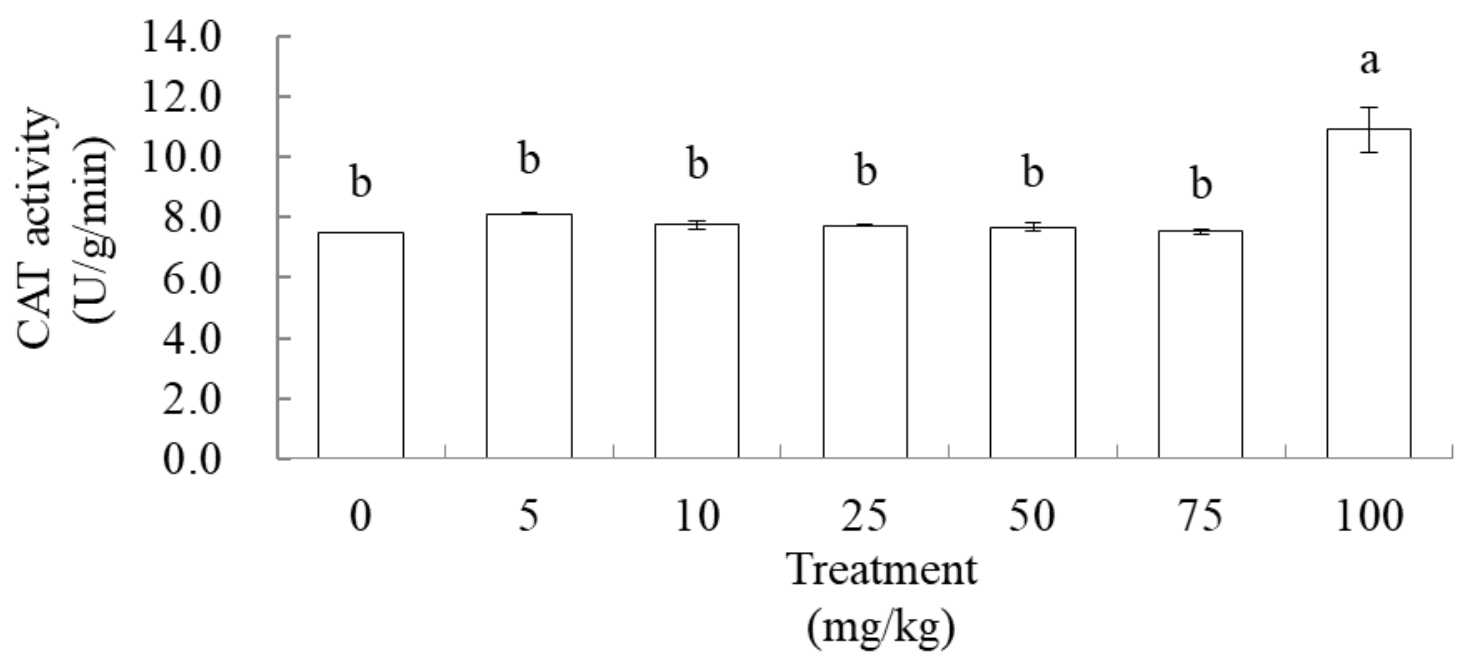

Fig. 3 CAT activity of $P$. frutescens

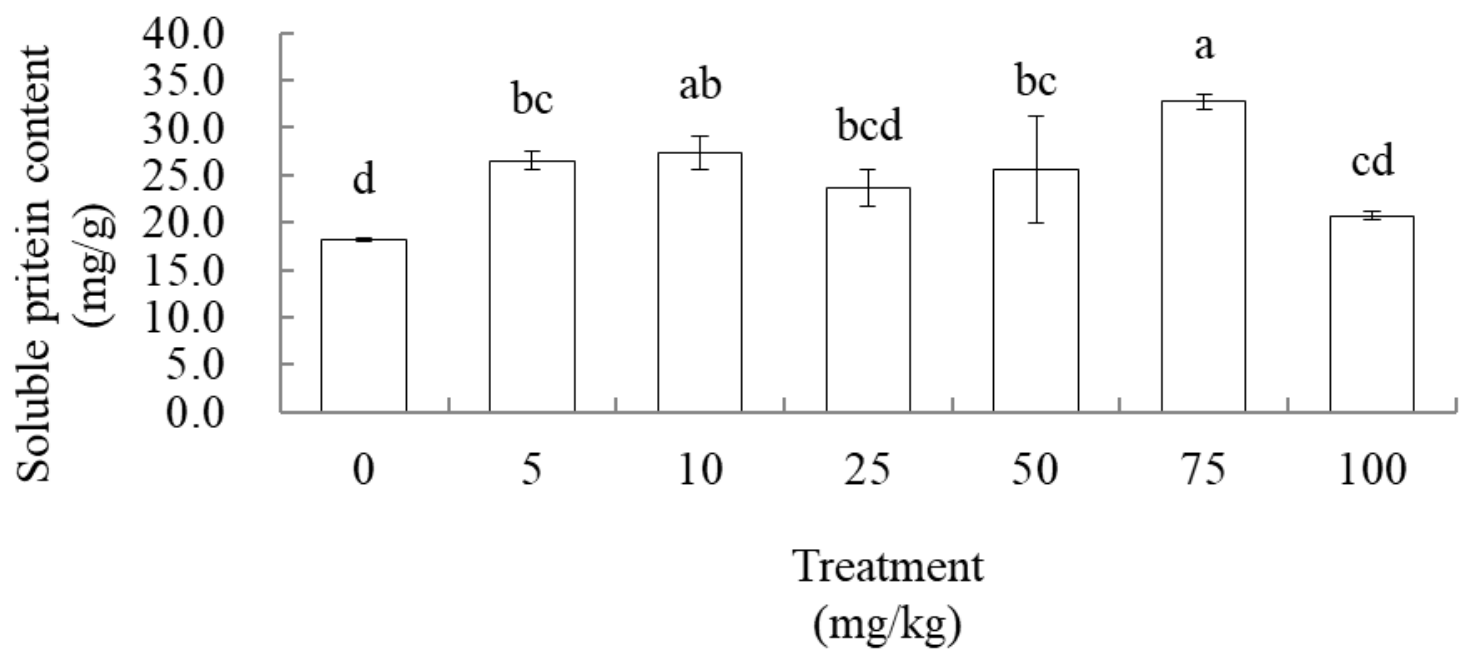

Fig. 4 Soluble protein content of $P$. frutescens 
Soluble Protein Content of $\boldsymbol{P}$. frutescen. With Se concentrations increased, soluble protein contents increased firstly and then decreased, and reached the peak when soil Se concentration was $75 \mathrm{mg} / \mathrm{kg}$ (Fig. 4). When Se concentrations were 5, 10, 25, 50 and $75 \mathrm{mg} / \mathrm{kg}$, soluble protein contents significantly increased by $46.16 \%, 51.01 \%, 30.46 \%, 41.17 \%$ and $80.28 \%$ respectively. And when Se concentration was $100 \mathrm{mg} / \mathrm{kg}$, soluble protein content was not significantly different from control.

\section{Conclusions}

Under the condition of Se treatment, with the increase of Se concentration, the activities of SOD, POD, CAT and soluble protein contents showed different trends. But when Se concentration was $100 \mathrm{mg} / \mathrm{kg}$, activities of SOD, POD and CAT reached the peak. However, soluble protein content reached the peak when Se concentration was $75 \mathrm{mg} / \mathrm{kg}$. In conclusion, Se treatment can improve antioxidant enzyme activity of $P$. frutescens, and $100 \mathrm{mg} / \mathrm{kg}$ Se was the best treatment. However, Se treatment also can improve soluble protein content of $P$. frutescens, and $75 \mathrm{mg} / \mathrm{kg}$ Se was the best treatment.

\section{Acknowledgements}

This work was financially supported by the Application Infrastructure Project of Science and Technology Department of Sichuan Province (2016JY0258).

\section{References}

[1] K.M Woo, J.Y Han, W.S Suh, J.H Lee and K.R Lee: Bulletin of the Korean Chemical Society Vol. 35(2014), p. 2151.

[2] M.Z Lslam, M.A Mele, J.P Baek and H.M Kang: Notulae Botanicae Horti Agrobototanici Cluj-Napoca Vol. 46(2018), p. 388.

[3] M Edelstein, D Berstein, M Shenker, H Azaizeh and M Benhur: Hortscience Vol. 51(2016), p. 1050 .

[4] G.F. Shi, J. Zhang and H.J. Li: Journal of Trace Elements and Health Research Vol. 18(2001), p. 51.

[5] K Sandeep Prabhu and Xin Gen Lei: Advances in Nutrition Vol. 7(2016), p. 415.

[6] X.B. Zhou, H.Y. Wang and F.D. Xie: Journal of Liaoning Agricultural Sciences Vol. 1 (2002), p. 36.

[7] M Djanaguiraman, P.V.V Prasad and M Seppanen: Plant Physiology and Biochemistry Vol. 48(2010), p. 999.

[8] Z.B. Hao, J. Cang and Z. Xu: Plant Physiology Experiment (Harbin Institute of Technology Press, Harbin, China 2004). 